\title{
Initial oral biofilm formation on titanium implants with different surface treatments: An in vivo study
}

\author{
Cyntia Ferreira Ribeiro ${ }^{a}$, Karina Cogo-Müller ${ }^{\mathrm{b}, *}$, Gilson Cesar Franco ${ }^{\mathrm{c}}$, \\ Laís Regiane Silva-Concílio ${ }^{\mathrm{a}}$, Márcia Sampaio Campos ${ }^{\mathrm{d}}$, Sigmar de Mello Rode ${ }^{\mathrm{e}}$, \\ Ana Christina Claro Neves ${ }^{a}$
}

\footnotetext{
a Department of Prosthodontics, Dentistry School, University of Taubaté Rua: Expedicionário Ernesto Pereira, 110 Centro, Taubaté, SP 12020-330, Brazil ${ }^{\mathrm{b}}$ Faculty of Pharmaceutical Sciences, University of Campinas (UNICAMP), Rua Sérgio Buarque de Holanda, 250, CB-II - sala E06 - 2 Piso, 13083-859, Campinas, SP, Brazil

${ }^{\mathrm{c}}$ Department of General Biology, Area of Physiology and Pathophysiology, State University of Ponta Grossa Av. General Carlos Cavalcanti, 4748 Uvaranas, Ponta Grossa, PR 84030-900, Brazil

'Department of Cariology, Restorative Sciences and Endodontics, School of Dentistry, University of Michigan, 1011N University Ave, Ann Arbor 48109, MI, USA

e Department of Dental Materials and Prosthodontics, Science and Technology Institute, Paulista State University "Júlio de Mesquita Filho" (UNESP), Av. Eng.

Francisco José Longo, 777 Jardim São Dimas, São José dos Campos, SP 12245-000, Brazil
}

\section{A R T I C L E I N F O}

\section{Article history:}

Received 13 May 2015

Received in revised form 30 March 2016 Accepted 8 May 2016

\section{Keywords:}

Biofilm

Titanium

Implants

Surface properties

Streptococcus oralis

\begin{abstract}
A B S T R A C T
Objective: The aim of this study was to examine in vivo the initial bacterial adhesion on titanium implants with different surface treatments.

Design: Ten subjects wore oral splints containing machined pure titanium disks (Ti-M), acid-etched titanium (Ti-AE) and anodized and laser irradiated disks (Ti-AL) for $24 \mathrm{~h}$. After this period, disks were removed from the splints and adherent bacteria were quantified by an enzymatic assay to assess total viable bacteria and by Real Time PCR to evaluate total bacteria and Streptococcus oralis levels. Additionally, the initial adherent microorganisms were visualized by scanning electron microscopy (SEM). Titanium surface morphology was verified using SEM, and roughness was evaluated by profilometer analysis.

Results: Regarding titanium surface roughness, Ti-AL $(1.423 \pm 0.397)$ showed significantly higher Ra values than did Ti-M $(0.771 \pm 0.182)$ and Ti-AE $(0.735 \pm 0.196)(\mathrm{p}<0.05$, ANOVA - Tahame). Ti-AE and Ti-AL presented roughened micro-structure surfaces characterized by open pores, whereas Ti-M showed long grooves alternating with planed areas. Comparing the Ti-M, Ti-AE and Ti-AL groups for viable bacteria (MTT assay), total bacteria and S. oralis quantification (qPCR), no significant differences were observed among these three groups ( $p>0.05$, ANOVA - Tahame). SEM images showed similar bacterial adhesion on the three titanium surfaces, predominantly characterized by cocci and several bacilli, indicating an initial colonization of the oral biofilm.

Conclusion: In conclusion, roughness and microtopography did not stimulate initial biofilm formation on titanium surfaces with different surface treatments.
\end{abstract}

(c) 2016 Elsevier Ltd. All rights reserved.

\section{Introduction}

Dental implants are routinely used to replace lost teeth and restore aesthetic function, phonetics and mastication (Astrand, Ahlqvist, Gunne, \& Nilson, 2008; Lekholm et al., 1999; Lekholm, Grondahl, \& Jemt, 2006). The success of implants depends on the integration of the implant to the bone and mucosal connective

\footnotetext{
* Corresponding author.

E-mail addresses: karicogo@hotmail.com, karicogomuller@gmail.com (K. Cogo-Müller).
}

tissue as well as the absence of inflammation and infection in the surrounding tissues (Burgers et al., 2010).

Titanium is a biocompatible material and has been widely used in dental implants. Various treatments on the surfaces of titanium implants have been used to improve the rate of osseointegration (Albrektsson and Wennerberg, 2004; Meirelles, Arvidsson, Albrektsson, \& Wennerberg, 2007; Schwartz-Filho, Morandini, Ramos-Junior, Jimbo, \& Santos, 2012) and to stimulate proper interactions between the implant and the oral mucosa (Wennerberg et al., 2011). However, these modifications generally promote alterations in roughness, surface free energy, wettability, and 
chemical composition, which may lead to increased bacterial adhesion and biofilm formation (Al-Ahmad et al., 2013; Burgers et al., 2010; Rasperini, Maglione, Cocconcelli, \& Simion, 1998; Teughels, Van Assche, Sliepen, \& Quirynen, 2006). Among the surface properties that can interfere with bacterial adhesion, surface roughness has been shown to be the most relevant (Teughels et al., 2006). However, it is still debatable whether and to what extent roughness can affect biofilm formation (Teughels et al., 2006; Schmidlin et al., 2013).

Although implant surfaces are sterile, once they are introduced to the oral cavity, bacteria will adhere to the surrounding salivary pellicle (Elter et al., 2008). This initial bacterial adhesion can develop to a mature biofilm as favored by a proper environment, which can lead to shifts in the composition and virulence of microorganisms. The biofilm composition and virulence together with an immune-inflammatory response can cause peri-implantitis and peri-implant mucositis (Mombelli and Decaillet, 2011).

Despite trying to mimic the conditions of the oral cavity, in vitro experiments do not adequately represent the characteristics of this cavity considering the diversity of microorganisms, the presence of saliva and shearing forces, the host immune response and the characteristics of individual patients. It is known that initial bacterial adhesion is essential to determine the organization, diversity and strength of the biofilm (Busscher, Bos, \& van der Mei, 1995; Kolenbrander, Andersen, Kazmerzak, \& Wu, 1999; Marsh and Devine, 2011). Therefore, in vivo studies of adhesion and biofilm formation are needed to understand the interaction between bacteria and implant surfaces.

The development of implant surfaces that promote improved osseointegration without strengthening bacterial adhesion is important to the clinical success of implants. Among other surface treatments are the acid-etching and anodized and laser irradiated treatments, which have been used to modify the surface of implants in order to improve integration of implant to the bone. Therefore, the aim of the present study was to evaluate in vivo the initial biofilm formation on acid-etched and anodized and laser irradiated surfaces compared with machine-treated surfaces. Titanium surface morphology was determined using scanning electron microscopy (SEM) and roughness was evaluated by profilometer analysis. Additionally, the initial adherent microorganisms were visualized by SEM and quantified by an enzymatic assay (MTT assay) and Real Time PCR.

\section{Material and methods}

\subsection{Titanium specimens and surface characterization}

Three different types of titanium specimens in disks $2 \mathrm{~mm}$ in thickness and $10 \mathrm{~mm}$ in diameter were provided by Conexão Implant Systems (São Paulo, Brazil). Machined pure titanium disks (Ti-M) were used as controls, while acid-etched titanium (Ti-AE) and anodized and laser irradiated disks (Ti-AL) were used in the experimental groups. Acid-etched titanium is used for the Master Porous $^{\circledR}$ implant system, and anodized and laser irradiated titanium is used for the Vulcano Actives ${ }^{\mathbb{R}}$ dental implant system.

The surface roughness of all specimens used in the in vivo experiments $(n=20)$ was determined with a Mitutoyo Surftest-211 Surface Roughness Tester Profilometer (Kawasaki, Kanagawa, Japan). Measurements were performed using a cut-off value of $0.5 \mathrm{~mm}(\lambda \mathrm{c})$ and a speed of $0.1 \mathrm{~mm} / \mathrm{s}$. Three measurements were performed in the longitudinal direction and three in the transversal direction, and the scanning area was the limit of the disk diameter (Duarte, Reis, de Freitas, \& Ota-Tsuzuki, 2009). The Roughness Average ( $\mathrm{Ra}$ ) parameter measures the average surface roughness analyzed by considering the peaks and valleys in the midline. The average roughness depth $(\mathrm{Rz})$ parameter is defined as the difference between the five highest peaks and the five lowest peaks.

Scanning electron microscopy (SEM) was performed to visualize the titanium surfaces (Quanta 650 FEG $^{\text {TM }}$, FEI Company, Japan). Three specimens for each group were fixed on metal stubs and imaged with a magnification of $\times 2.500, \times 5.000$ and $\times 10.000$.

\subsection{In vivo bacterial adhesion assay}

After ethical approval by the Ethics Committee of the Tiradentes University (protocol \# 250511 - Aracaju, Sergipe, Brazil), informed written consent was provided by all subjects. Ten healthy subjects were selected to participate in the study. Subjects had overall satisfactory health (absence of endocrine disorders; hormonal, hematologic, immune, or nutritional changes; or any diseases or drugs that alter salivary flow), salivary flow of $1,5 \mathrm{~mL} / \mathrm{min}$ and excellent oral conditions (no carious lesions and periodontally healthy). Those individuals who had less than $4 \mathrm{~mm}$ probing depth and who did not present clinical attachment loss and gingival inflammation were considered to be periodontally healthy (Lopez, Smith, \& Gutierrez, 2002). Individuals who had used antibiotics or antibacterial mouth rinses in the last six months prior to the study were not included.

For the in vivo bacterial adhesion assay, subjects wore an acrylic splint in the upper jaw for $24 \mathrm{~h}$. A disk of each of the three titanium specimens (Ti-M, Ti-AE and Ti-AL) was fixed on each buccal side of the splint (right and left), in the region of the premolars and molars, to avoid biofilm disruption by tongue and cheeks (Fig. 1). Specimens were fixed with light-cured resin (Filtek P60, 3 M Espe, Saint Paul, MN, USA). Prior to use, the splints were disinfected by ultrasonication and immersion in a $1 \%$ sodium hypochlorite solution for ten mins. After that, the splints were washed three times in sterile distilled water for one min to remove any residual hypochlorite.

The splints were worn for $24 \mathrm{~h}$ and subjects were instructed to only remove the splints during meals and tooth brushing. During splint use, subjects were instructed to maintain their eating habits and oral hygiene routines (Grossner-Schreiber et al., 2001). After this period, the disks were carefully removed from the splints and gently washed 2 times in $\mathrm{NaCl} 0.9 \%(\mathrm{w} / \mathrm{v})$ to remove non-adhered cells. Some of the disks $(n=3)$ were used for microscopic qualitative analysis by Scanning Electron Microscopy (SEM). The other disks were placed in polystyrene tubes containing saline solution and then vortexed for $1 \mathrm{~min}$ to detach the bacteria. This suspension was then used for bacterial quantification by the MTT assay and Real Time PCR ( $n=17)$.

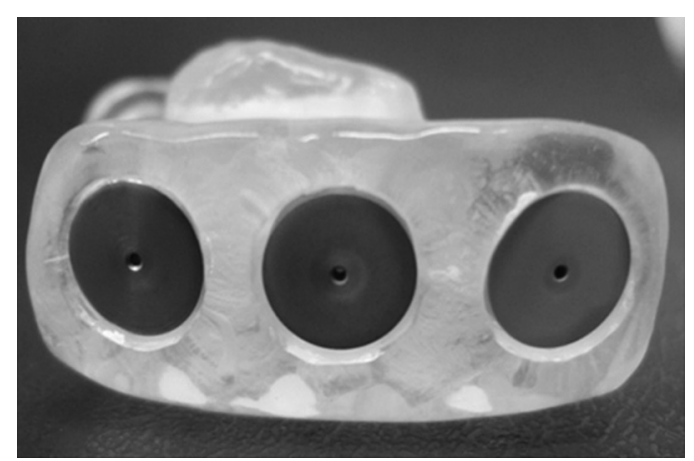

Fig. 1. Buccal view of the acrylic splint with the three titanium specimens set in niches. 


\subsection{MTT assay}

The MTT (3-(4,5-dimethylthiazol-2-yl)-2,5-diphenyltetrazolium bromide) assay was performed to quantify total viable bacterial cells adhered to the titanium disks. This assay was performed in 96-well plates using the Cell Titer 96 one solution cell proliferation assay according to the manufacturer's instructions (Promega, Madison, Wisconsin, USA). Briefly, $50 \mu \mathrm{L}$ from the bacterial suspension obtained from the disks were added to each well containing $20 \mu \mathrm{L}$ of Cell Titer 96 solution. The plates were protected from the light and incubated at $37^{\circ} \mathrm{C}$ for $3 \mathrm{~h}$. After incubation, optical density at $490 \mathrm{~nm}$ was analyzed using a microplate spectrophotometer (Asys Expert PlusMicroplate Reader, Biochrom, Cambridge, UK).

\subsection{Real time $P C R$}

Specific primers and probes were used for quantification of total bacteria and Streptococcus oralis adhered to the titanium surfaces. Universal primers and probes were previously designed based on 16S rRNA gene sequences (Nonnenmacher, Dalpke, Mutters, \& Heeg, 2004) while S. oralis primers were designed using the Primer3 tool (www.bioinformatics.nl/primer3plus) and the rgg gene sequence (Park, Lee, \& Kim, 2010). Primers and probes are listed in Table 1 and each sequence was searched against nucleotide sequences using BLAST to confirm target specificity (http://blast.ncbi.nlm.nih.gov/Blast.cgi).

Genomic DNA was extracted from $500 \mu \mathrm{L}$ of the bacterial suspension using the PureLink ${ }^{\mathrm{TM}}$ Genomic DNA Purification Kit (Life technologies, Carlsbad, CA, USA) according to the manufacturer's instructions.

For quantification of bacterial cells, standard curves were constructed using cultures of S. oralis and Escherichia coli for universal quantification. Cultures of $S$. oralis and $E$. coli were grown on plates of Trypitic Soy Agar (Difco Co., Detroit, MI, USA) for $24 \mathrm{~h}$ at $37^{\circ} \mathrm{C}$, under aerobic and $5 \% \mathrm{CO}_{2}$ conditions, respectively. Genomic DNA (gDNA) was extracted and quantified using optical density analysis (Nanodrop 200010 spectrophotometer, Thermoscientific, Scottsdale, AZ, USA). The mass of gDNA that correspond to copy numbers of target nucleic acid sequences was calculated considering the genome size of each bacterium. Standard curves were constructed to dilute DNA to defined concentrations from $10^{7}$ to 10 copies, which correspond to the same amount of bacterial cells.

Quantitative PCR was performed in a $25 \mu \mathrm{L}$ reaction volume containing $12.5 \mu \mathrm{L}$ of $2 \mathrm{x}$ TaqMan Universal PCR Master Mix (Life Technologies, Carlsbad, CA, USA), $300 \mathrm{nM}$ of forward and reverse primers, $250 \mathrm{nM}$ of TaqMan probe and $2.5 \mu \mathrm{L}$ of template DNA in 96-well plates. Cycling conditions were as follows: $95^{\circ} \mathrm{C}$ for 10 mins, followed by 40 cycles at $95^{\circ} \mathrm{C}$ for $15 \mathrm{~s}$ and $60^{\circ} \mathrm{C}$ for $1 \mathrm{~min}$. The reactions were performed on an ABI Prism 7500 Fast System (Life Technologies). Cycle threshold $(\mathrm{Ct})$ values from samples were plotted into standard curves to convert $\mathrm{Ct}$ values into number of

Table 1

Primers and Probes sequences for the detection of total bacteria and S. oralis by qPCR.

\begin{tabular}{lll}
\hline Bacteria & Primers/Probe $\left(5^{\prime}-3^{\prime}\right)$ & Reference \\
\hline Universal & (F) TGGAGCATGTGGTTTAATTCGA & $\begin{array}{l}\text { Nonnenmacher et al. } \\
\text { (R) TGCGGGACTTAACCCAACA } \\
\text { (Probe) CACGAGCTGACGACA(AG) }\end{array}$ \\
& CCATGCA & \\
S. oralis & (F) TTGGCTCAATTCCCTTTGAC & $\begin{array}{l}\text { Designed in the present } \\
\text { study }\end{array}$ \\
& $\begin{array}{l}\text { (R) GTCCAAACAAGCCACCACTT } \\
\text { (Probe) ACAACATATCAACAGGCGCA }\end{array}$ & \\
\hline
\end{tabular}

$\mathrm{F}$, forward primer; $\mathrm{R}$, reverse primer. bacterial cells (Casarin, Ribeiro Edel, Mariano, Casati, \& Goncalves, 2010; Dolezel, Bartos, Voglmayr, \& Greilhuber, 2003).

\subsection{Statistical analyses}

Numerical variables were described as mean and standard deviation. Data from roughness and microbiological assays were compared using the One Way ANOVA test followed by post-test Tamhane. Levene's test was performed to assess variance homogeneity from data. Statistical software (SPSS Statistics version 22.0, IBM, New York, USA) was used to conduct these analyses. The significance level was set at $5 \%$.

\section{Results}

\subsection{Characterization of titanium surfaces}

Regarding the surface roughness, Ti-AL showed significantly higher Ra and Rz values than did Ti-M and Ti-AE $(\mathrm{p}<0.05$, ANOVA - Tahame). The Ra/Rz ratios between Ti-M and Ti-AE were not different ( $p>0.05$, ANOVA). Ra and $\mathrm{Rz}$ values are described in Table 2.

The SEM images of the disks are represented in Fig. 2, and show the different microtopography aspects of theses surfaces. SEM images of Ti-M surfaces showed long grooves along the entire titanium surface alternating with planed areas. Ti-AE presented roughened micro-structures characterized by open pores occupying the entire surface. Ti-AL also showed micro-pores in its surface, but they appeared to be more dispersed and rounded than the Ti-AE pores.

\subsection{In vivo evaluation of bacterial adhesion to titanium surfaces}

Bacterial adhesion to titanium specimens was evaluated by a viability test (MTT), qPCR and SEM images. While the MTT test assesses the number of viable bacteria by the reduction reaction of the tetrazolium bromide (MTT), the water-soluble yellow dye that can be reduced to water-insoluble purple formazan crystals by the dehydrogenase system of active cells, qPCR detected the total number of attached microorganisms, independent of their viability.

Optical density values representing bacterial viability in the MTT assay are shown in Table 3. Comparing the Ti-M, Ti-AE and Ti-AL groups, no significant difference was observed among these groups, indicating that the number of viable bacteria in biofilms on the disks was similar for all groups tested $(p>0.05$, ANOVA, Tahame).

The results found in MTT assay were in agreement with those obtained from the PCR analysis. Fig. 3 represents the logarithmic representation of total bacterial levels and Streptococcus oralis levels per disk. Ti-M, Ti-AE and Ti-AL showed the same similar levels of adhesion considering the total number of bacteria and the total number of S. oralis adhered to the implant surfaces (ANOVA).

The implant surfaces were predominantly colonized in monolayers as isolated cells or aggregates that were distributed randomly in the surface. Machined surfaces showed more isolated cells than did the other surfaces. However, the Ti-AE and Ti-AL

Table 2

Mean and standard deviation for Ra and Rz values in $\mu \mathrm{m}$.

\begin{tabular}{lllll}
\hline Parameters & Ti-M & Ti-AE & Ti-AL & $p$ value* $^{*}$ \\
& $\mathrm{n}=20$ & $\mathrm{n}=20$ & \\
\hline Ra $(\mu \mathrm{m})$ & $0.8 \pm 0.2^{\mathrm{a}}$ & $0.7 \pm 0.2^{\mathrm{a}}$ & $1.4 \pm 0.4^{\mathrm{b}}$ & $<0.0001$ \\
$\operatorname{Rz}(\mu \mathrm{m})$ & $3.6 \pm 0.8^{\mathrm{a}}$ & $4 \pm 0.8^{\mathrm{a}}$ & $7.7 \pm 2.0^{\mathrm{b}}$ & $<0.0001$ \\
\hline
\end{tabular}

*ANOVA - Tahame.

Different letters ( $\mathrm{a}$ and $\mathrm{b}$ ) represent difference among groups. 

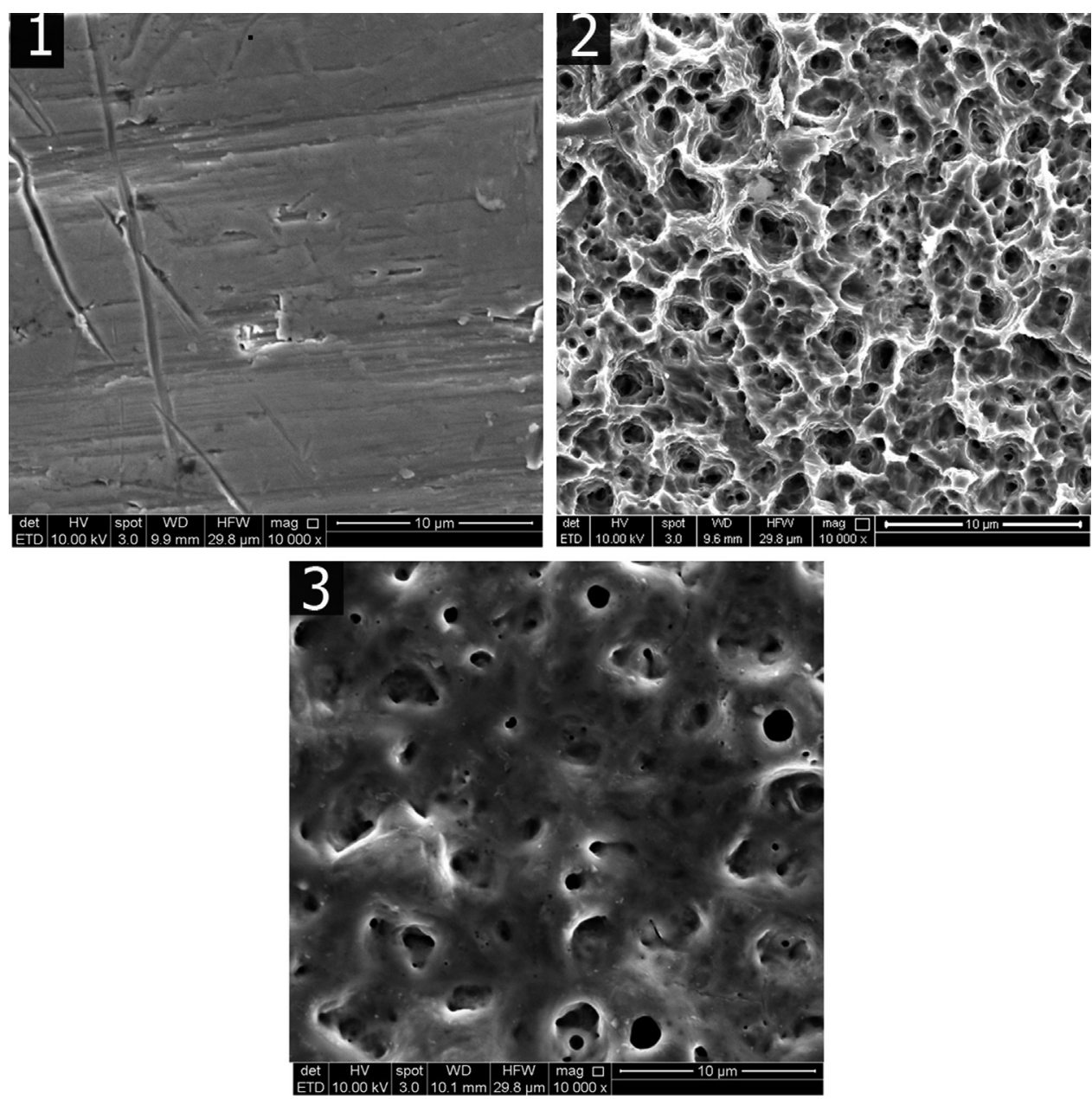

Fig. 2. Scanning electron microscopy $(\times 10.000)$ for Ti-M (1), Ti-AE (2) and Ti-AL (3) before in vivo experiments.

surfaces harbored more bacterial aggregates than single cells, and many of these aggregates were found lodged inside the microcavities of the titanium surfaces. This fact hindered an absolute quantification of the SEM images. However, these images were important to determine the type of colonization on titanium surfaces that occurred within $24 \mathrm{~h}$ of exposure to the oral cavity. It is noteworthy that the vast majority of surfaces were colonized by cocci, which is often found during initial colonization of oral biofilm. SEM images are represented in Fig. 4.

\section{Discussion}

Implant surface modifications have been attempted to increase the rate and extent of osseointegration; in others words, modification of the micro and nano-topographies seems to stimulate osteoblast activity, extracellular matrix formation and bone mineralization (Gutwein and Webster, 2004; Thakral, Thakral, Sharma, Seth, \& Vashisht, 2014). However, it is still unclear if these modifications in surface characteristics, such as increased roughness, surface free energy, wettability and other

Table 3

Mean standard deviation for bacterial viability through MTT analysis.

\begin{tabular}{lll}
\hline Groups & OD (Meand and SD) & $p$ value \\
\hline Ti-M & $0.19( \pm 0.05)$ & 0.89 \\
Ti-AE & $0.14( \pm 0.08)$ & \\
Ti-AL & $0.12( \pm 0.07)$ & \\
\hline
\end{tabular}

OD, optical density at $490 \mathrm{~nm}$. surface properties, would induce biofilm formation and further contribute to the initiation and development of peri-implant infections (Al-Ahmad et al., 2013; Burgers et al., 2010; Rasperini et al., 1998; Schmidlin et al., 2013; Teughels et al., 2006). The present study evaluated the initial biofilm formation in vivo on three titanium surfaces, and despite high differences in roughness and topography, bacterial adhesion was quite similar on all surfaces. These results do not support previous studies that indicated that enhanced roughness would improve bacterial colonization.

The present investigation examined bacterial adhesion on three different titanium surfaces, named Ti-M (machined pure titanium), Ti-AE (acid-etched titanium) and Ti-AL (anodized and laser irradiated disks). Biofilm was allowed to form on these disks for $24 \mathrm{~h}$ in the oral cavity of 10 subjects, and bacterial adhesion was very similar among groups. Ti-M and Ti-AE presented a roughness of approximately $0.7 \mu \mathrm{m}$ while Ti-AL showed a mean roughness of $1.4 \mu \mathrm{m}$; Ti-M and Ti-AE had minimally rough surfaces and Ti-AL had a moderately rough surface (Albrektsson and Wennerberg, 2004). Although there was a considerable difference in roughness among the Ti-M/Ti-AE and Ti-AL materials bacterial adhesion was not enhanced on the Ti-AL surfaces. These findings are in line with previous studies. An in vivo study showed that after 5 days, biofilm formation was very similar among titanium and zirconia implant surfaces with roughness ranging from 21.6 to $544.3 \mathrm{~nm}$ (Al-Ahmad et al., 2013). A recently published in vitro study revealed that titanium surfaces with roughness differences of $0.9 \mu \mathrm{m}$ (from 0.3 to $1.2 \mu \mathrm{m}$ ) promoted comparable multi-species biofilm formation 


\section{Total bacteria}

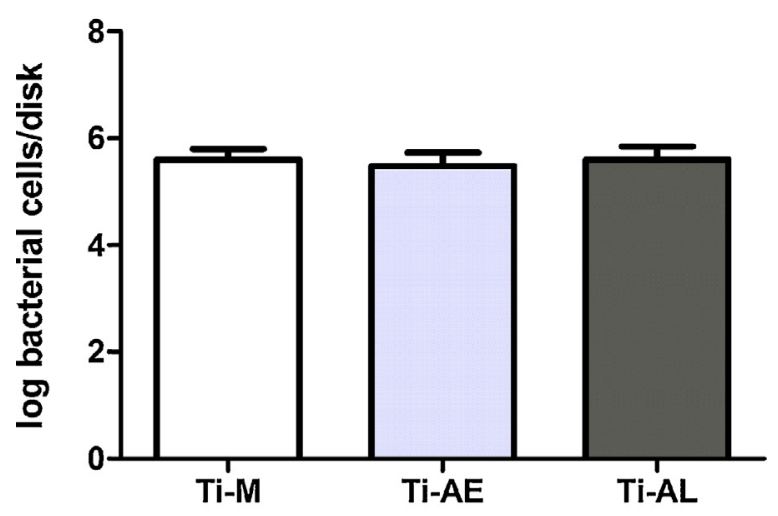

S. oralis

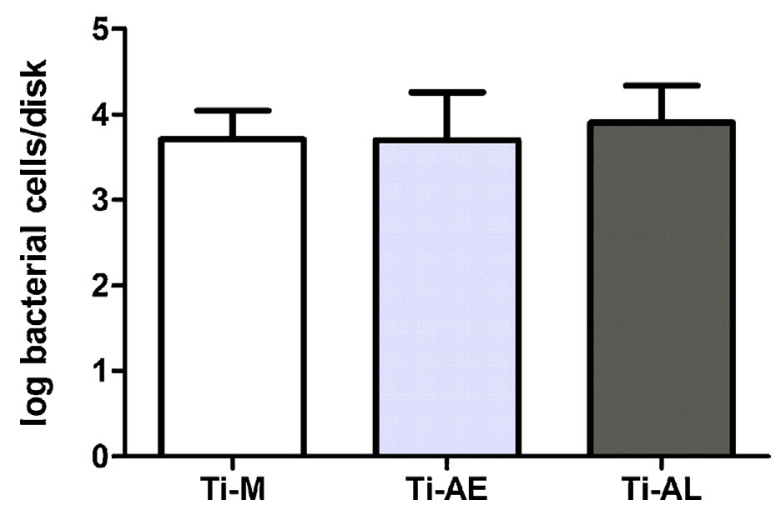

Fig. 3. Mean and standard deviation of logarithmic values for total bacterial levels and $S$. oralis levels per disk. No differences were found among the groups (ANOVA).

on their surface (Schmidlin et al., 2013). P. gingivalis colonized equally titanium surfaces with Ra from $155 \mathrm{~nm}$ to $449.42 \mathrm{~nm}$.

It has been shown that rougher surfaces are more susceptible to harbor higher amounts of bacteria, mainly in surfaces with Ra values higher than $2 \mu \mathrm{m}$ (Almaguer-Flores et al., 2012; Rimondini et al., 1997). However, some studies have also shown that moderately rough surfaces $(1-2 \mu \mathrm{m})$ can also stimulate bacterial colonization when comparing to minimally rough $(0.5-1 \mu \mathrm{m})$ and smooth surfaces $(<0.5 \mu \mathrm{m})$ (Bollen et al., 1996; Burgers et al., 2010; Frojd et al., 2011). It is still controversial whether and to what extent minor changes in roughness can affect biofilm formation; therefore, we tested if moderately to minimally rough surfaces would be different from each other in bacterial adhesion patterns. We found that from minimally to moderately rough surfaces, no improvement in initial biofilm formation occurs. Previously, a study showed that $P$. gingivalis colonized equally titanium surfaces with Ra from $155 \mathrm{~nm}$ to $449.42 \mathrm{~nm}$, but only when roughness was highly reduced, bacterial adhesion also decreased $(\mathrm{Ra}=34 \mathrm{~nm})$ (Amoroso, Adams, Waters, \& Williams, 2006). Therefore, it is possible that only high differences in roughness among surfaces promotes differences in bacterial adhesion. Future studies with very smooth and very rough surfaces should be conducted to confirm this hypothesis.

Roughening of the surface can increase the area available for bacterial adhesion and also protect against shear forces in the oral cavity (Teughels et al., 2006). Ti-AE and Ti-AL materials had pores and grooves on their surfaces, which may contribute to bacterial adhesion and sheltering; however, these characteristics did not seem to influence on initial bacterial adhesion to either material. Previous studies showed that roughness and topography can promote biofilm formation (Al-Ahmad et al., 2013; Burgers et al., 2010), mainly in surfaces with roughness values $>0.2 \mu \mathrm{m}$ (Bollen et al., 1996; Teughels et al., 2006). This observation was not supported by our data. In this study, differences between bacterial colonization were less than 1 log, as changes bellow 1 log step were considered to be irrelevant to biofilm formation (Schmidlin et al., 2013). However, some studies that reported that roughness interferes with bacterial adhesion considered changes bellow 1 log step during bacterial assessment (Al-Ahmad et al., 2013; Almaguer-Flores et al., 2012; Burgers et al., 2010). Therefore, differences in findings among studies may be explained, in part, by differences in study design such as in vivo or in vitro conditions, logarithmic ratio of adhered bacteria, time of biofilm formation, presence of saliva, and other factors.

The first bacterial layers in the biofilm determine the strength, arrangement and diversity of species that will later colonize the biofilm (Busscher et al., 1995; Kolenbrander et al., 1999; Marsh and Devine, 2011; Rimondini et al., 1997). It seems that the influence of roughness, topography and other properties of the implant material are compensated for by biofilm maturation (Al-Ahmad et al., 2010; Nakazato, Tsuchiya, Sato, \& Yamauchi, 1989). Therefore, the present study investigated the bacterial adhesion to titanium surfaces in the oral cavity for $24 \mathrm{~h}$ during initial biofilm development. Other studies also aimed to examine this initial period of biofilm formation, and in some of these investigations, bacterial adhesion was also similar among different surfaces. In a multi-species biofilm formed in vitro, roughness and wettability did not modify bacterial colonization during $16.5 \mathrm{~h}$ of biofilm growth (Schmidlin et al., 2013). Other in vitro investigations showed that roughness promoted adhesion during the first $2 \mathrm{~h}$ of biofilm establishment, but at $14 \mathrm{~h}$ of growth, the biofilms were very similar in biomass (Frojd et al., 2011). Thus, this study showed that differences in the surface characteristics may not affect the number of bacteria adhered to the surface even when considering the initial period of biofilm development.

In the present study, it was not possible to compare bacterial counting from qPCR and SEM images. From SEM images, we could not determine exactly the number of bacteria adhered to the disks, mainly for surfaces with pores and grooves (Ti-AE and Ti-AL materials). In these surfaces, bacteria were sheltered in pores, which made difficult bacterial counting. However, we estimated by visual counting from Ti-M images that there were around $6 \times 10^{6}$ cells per $\mathrm{cm}^{2}$ (data not shown; estimated number). Therefore, it is possible that there was a discrepancy between images and qPCR data of around 1-1.5 log cells. We believe that this difference in quantities may have occurred due to sample manipulation and technique limitations. Disk vortexing, centrifugation of samples, DNA extraction, pipetting, etc., may have contributed for bacterial loosing. In addition, procedures to detach biofilm from surfaces, including vortexing, have some limitations as they could not remove all bacteria attached from surfaces. However, as all qPCR samples were equally processed, this bacterial lost was similar for all samples and therefore did not interfered with data reliability.

Streptococci (S. oralis, S. mitis, and S. sanguis) are the initial colonizers in dental biofilm and begin adhesion within the first $4 \mathrm{~h}$ of pellicle formation (Rosan and Lamont, 2000; Subramani, Jung, Molenberg, \& Hammerle, 2009). S. oralis populations were investigated here by qPCR to represent the initial colonization of biofilm, and similar levels of these bacteria were found among groups. Cocci were the predominant bacteria in SEM analyses, and few bacilli were adhered to the surfaces, which also represented an initial biofilm profile. It is possible that some bacteria were entrapped in groves and pores instead of being adhered to the surface. However, bacterial aggregation was clearly observed on titanium substrata, confirming that bacteria were adhered to the surface. 

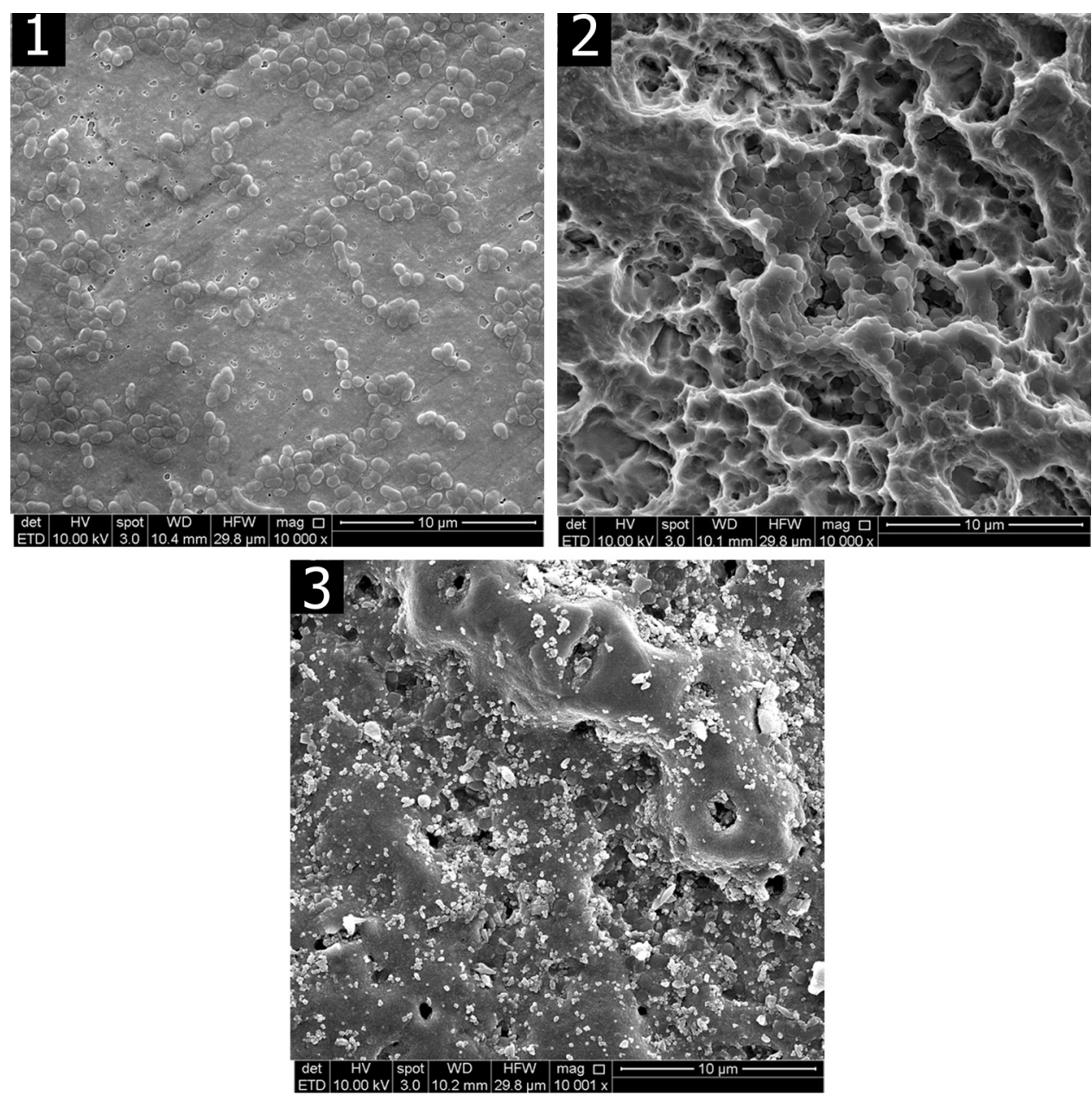

Fig. 4. Scanning electron microscopy $(\times 10.000)$ for Ti-M (1), Ti-AE (2) and Ti-AL (3) after in vivo experiments and colonization by oral microorganisms.

Although the present study was conducted in in vivo conditions, the experimental conditions used here were as close as possible to the conditions of initial bacterial colonization of the implant in clinical situations. However, a limitation of the present study was that it was conducted at the supragingival region, while in clinical practice, biofilm will develop on the implant in the subgingival sites. In addition, saliva and other coatings were showed to influence bacterial colonization to titanium surfaces (AlmaguerFlores et al., 2012; Wang, Liang, Cheng, Mac, \& Zhao, 2009). Although saliva has some influence on bacterial adhesion, we believe that in vivo studies bring more real conditions for the bacterial adhesion process. Further clinical studies providing subgingival samples need to be conducted to confirm the findings of the present study.

\section{Conclusion}

In summary, moderately rough surfaces and microtopography did not interfere with initial bacterial adhesion to titanium surfaces. From a clinical point of view, moderately rough implants will not increase biofilm formation as long as meticulous oral hygiene and preventive care are undertaken.

\section{Acknowledgments}

We would like to thank Conexão Implant Systems for donating the samples and Mrs Juliana Santos for technical assistance.

\section{References}

Al-Ahmad, A., Wiedmann-Al-Ahmad, M., Faust, J., Bachle, M., Follo, M., Wolkewitz, M., et al. (2010). Biofilm formation and composition on different implant materials in vivo. Journal of Biomedical Materials Research Part B Applied Biomaterials, 95(1), 101-109.

Al-Ahmad, A. Wiedmann-Al-Ahmad, M.,Fackler, A, Follo, M. Hellwig E. Bachle M. et al. (2013). In vivo study of the initial bacterial adhesion on different implant materials. Archives of Oral Biology, 58(9), 1139-1147.

Albrektsson, T., \& Wennerberg, A. (2004). Oral implant surfaces: part 1-review focusing on topographic and chemical properties of different surfaces and in vivo responses to them. The International Journal of Prosthodontics, 17(5), 536-543.

Almaguer-Flores, A., Olivares-Navarrete, R., Wieland, M., Ximenez-Fyvie, L. A., Schwartz, Z., \& Boyan, B. D. (2012). Influence of topography and hydrophilicity on initial oral biofilm formation on microstructured titanium surfaces in vitro. Clinical Oral Implants Research, 23(3), 301-307.

Amoroso, P. F., Adams, R. J., Waters, M. G., \& Williams, D. W. (2006). Titanium surface modification and its effect on the adherence of Porphyromonas gingivalis: an in vitro study. Clinical Oral Implants Research, 17(6), 633-637.

Astrand, P., Ahlqvist, J., Gunne, J., \& Nilson, H. (2008). Implant treatment of patients with edentulous jaws: a 20-year follow-up. Clinical Implant Dentistry and Related Research, 10(4), 207-217.

Bollen, C. M., Papaioanno, W., Van Eldere, J., Schepers, E., Quirynen, M., \& van Steenberghe, D. (1996). The influence of abutment surface roughness on plaque accumulation and peri-implant mucositis. Clinical Oral Implants Research, 7(3), 201-211.

Burgers, R., Gerlach, T., Hahnel, S., Schwarz, F., Handel, G., \& Gosau, M. (2010). In vivo and in vitro biofilm formation on two different titanium implant surfaces. Clinical Oral Implants Research, 21(2), 156-164.

Busscher, H. J., Bos, R., \& van der Mei, H. C. (1995). Initial microbial adhesion is a determinant for the strength of biofilm adhesion. FEMS Microbiology Letters, 128 (3), 229-234.

Casarin, R. C., Ribeiro Edel, P., Mariano, F. S., Nociti, F. H. Jr., Casati, M. Z., \& Goncalves, R. B. (2010). Levels of Aggregatibacter actinomycetemcomitans, Porphyromonas 
gingivalis, inflammatory cytokines and species-specific immunoglobulin $\mathrm{G}$ in generalized aggressive and chronic periodontitis. Journal of Periodontal Research, 45(5), 635-642.

Dolezel, J., Bartos, J., Voglmayr, H., \& Greilhuber, J. (2003). Nuclear DNA content and genome size of trout and human. Cytometry Part A the Journal of the International Society for Analytical Cytology, 51(2), 127-128 [author reply 129].

Duarte, P. M., Reis, A. F., de Freitas, P. M., \& Ota-Tsuzuki, C. (2009). Bacterial adhesion on smooth and rough titanium surfaces after treatment with different instruments. Journal of Periodontology, 80(11), 1824-1832.

Elter, C., Heuer, W., Demling, A., Hannig, M., Heidenblut, T., Bach, F. W., et al. (2008) Supra- and subgingival biofilm formation on implant abutments with different surface characteristics. The International Journal of Oral $\mathcal{E}$ Maxillofacial Implants, 23(2), 327-334.

Frojd, V., Chavez de Paz, L., Andersson, M., Wennerberg, A., Davies, J. R., \& Svensater G. (2011). In situ analysis of multispecies biofilm formation on customized titanium surfaces. Molecular Oral Microbiology, 26(4), 241-252.

Grossner-Schreiber, B., Griepentrog, M., Haustein, I., Muller, W. D., Lange, K. P., Briedigkeit, H., et al. (2001). Plaque formation on surface modified dental implants: an in vitro study. Clinical Oral Implants Research, 12(6), 543-551.

Gutwein, L. G., \& Webster, T. J. (2004). Increased viable osteoblast density in the presence of nanophase compared to conventional alumina and titania particles. Biomaterials, 25(18), 4175-4183.

Kolenbrander, P. E., Andersen, R. N., Kazmerzak, K., Wu, R., \& Palmer, R. J. Jr. (1999). Spatial organization of oral bacteria in biofilms. Methods in Enzymology, 310, 322-332.

Lekholm, U., Gunne, J., Henry, P., Higuchi, K., Linden, U., Bergstrom, C., et al. (1999). Survival of the Branemark implant in partially edentulous jaws: a 10-year prospective multicenter study. The International Journal of Oral E' Maxillofacial Implants, 14(5), 639-645.

Lekholm, U., Grondahl, K., \& Jemt, T. (2006). Outcome of oral implant treatment in partially edentulous jaws followed 20 years in clinical function. Clinical Implant Dentistry and Related Research, 8(4), 178-186.

Lopez, N. J., Smith, P. C., \& Gutierrez, J. (2002). Higher risk of preterm birth and low birth weight in women with periodontal disease. Journal of Dental Research, 81 (1), 58-63.

Marsh, P. D., \& Devine, D. A. (2011). How is the development of dental biofilms influenced by the host? Journal of Clinical Periodontology, 38(Suppl 11), 28-35.

Meirelles, L., Arvidsson, A., Albrektsson, T., \& Wennerberg, A. (2007). Increased bone formation to unstable nano rough titanium implants. Clinical Oral Implants Research, 18(3), 326-332.

Mombelli, A., \& Decaillet, F. (2011). The characteristics of biofilms in peri-implant disease. Journal of Clinical Periodontology, 38(Suppl 11), 203-213.
Nakazato, G., Tsuchiya, H., Sato, M., \& Yamauchi, M. (1989). In vivo plaque formation on implant materials. The International Journal of Oral E Maxillofacial Implants, 4 (4), 321-326.

Nonnenmacher, C., Dalpke, A., Mutters, R., \& Heeg, K. (2004). Quantitative detection of periodontopathogens by real-time PCR. Journal of Microbiological Methods, 59 (1), 117-125.

Park, H. K., Lee, H. J., \& Kim, W. (2010). Real-time PCR assays for the detection and quantification of Streptococcus pneumoniae. FEMS Microbiology Letters, 310(1), 48-53.

Rasperini, G., Maglione, M., Cocconcelli, P., \& Simion, M. (1998). In vivo early plaque formation on pure titanium and ceramic abutments: a comparative microbiological and SEM analysis. Clinical Oral Implants Research, 9(6), 357-364.

Rimondini, L., Fare, S., Brambilla, E., Felloni, A., Consonni, C., Brossa, F., et al. (1997). The effect of surface roughness on early in vivo plaque colonization on titanium. J Periodontol, 68(6), 556-562.

Rosan, B., \& Lamont, R. J. (2000). Dental plaque formation. Microbes and Infection/ Institut Pasteur, 2(13), 1599-1607.

Schmidlin, P. R., Muller, P., Attin, T., Wieland, M., Hofer, D., \& Guggenheim, B. (2013). Polyspecies biofilm formation on implant surfaces with different surface characteristics. Journal of Applied Oral Science: Revista FOB, 21(1), 48-55.

Schwartz-Filho, H. O., Morandini, A. C., Ramos-Junior, E. S., Jimbo, R., Santos, C. F., Marcantonio, E. Jr., et al. (2012). Titanium surfaces with nanotopography modulate cytokine production in cultured human gingival fibroblasts. Journal of Biomedical Materials Research Part A, 100(10), 2629-2636.

Subramani, K., Jung, R. E., Molenberg, A., \& Hammerle, C. H. (2009). Biofilm on dental implants: a review of the literature. The International Journal of Oral $\varepsilon^{\prime}$ Maxillofacial Implants, 24(4), 616-626.

Teughels, W., Van Assche, N., Sliepen, I., \& Quirynen, M. (2006). Effect of material characteristics and/or surface topography on biofilm development. Clinical Oral Implants Research, 17(Suppl 2), 68-81.

Thakral, G., Thakral, R., Sharma, N., Seth, J., \& Vashisht, P. (2014). Nanosurface - the future of implants. Journal of Clinical and Diagnostic Research: JCDR, 8(5), ZE0710.

Wang, X., Liang, J., Cheng, J., Mac, W., \& Zhao, Y. (2009). Staphylococcus aureus adhesion to different implant surface coatings: an in vitro study. Surface and Coatings Technology, 203(22), 3454-3458.

Wennerberg, A., Frojd, V., Olsson, M., Nannmark, U., Emanuelsson, L., Johansson, P., et al. (2011). Nanoporous $\mathrm{TiO}(2)$ thin film on titanium oral implants for enhanced human soft tissue adhesion: a light and electron microscopy study. Clinical Implant Dentistry and Related Research, 13(3), 184-196. 